\title{
The Correlation between Tooth Health Care with Number of Caries in Autistic Students at Elementary and Junior High School for Disabled Students Bhakti Luhur Malang
}

\author{
Juwitasari $^{1^{*}}$, Ahsan $^{2}$ and Rita Rosita ${ }^{3}$ \\ ${ }^{I}$ Departement of Nursing, Faculty of Health Science, University of Muhammadiyah Malang, Jalan Bendungan Sutami 188, \\ Malang, Indonesia 65145 \\ ${ }^{2}$ Department of Nursing, Medical Faculty of Brawijaya University, Jalan Veteran Malang, Lowokwaru, Malang, Indonesia \\ 65145 \\ ${ }^{3}$ Department of Anatomy, Medical Faculty of Brawijaya University, Jalan Veteran Malang, Lowokwaru, Malang, Indonesia \\ 65145 \\ EEmail:juwita@umm.ac.id
}

Keywords: $\quad$ Autistic Student, Number of Caries, and Tooth Health Care.

Abstract: The student with autistic disorder may lead to severe tooth caries worse than normal people. Autistic students experience complex brain development disorders. The increased age of students with an autism spectrum disorder, cannot guarantee the ability to maintain tooth hygiene that causes the emergence of caries. This research identified the correlation between tooth health care with the number of tooth caries in autistic students. This observational analysis design with a cross-sectional method was applied in this research. The participants of this research were 24 students who met inclusion criteria. The result showed that all 24 autistic students suffering tooth caries. Students with poor dental health care tend to have a moderate number of dental caries in 1 student $(4.17 \%)$. Whereas for students with moderate dental health care, they have 6 moderate dental caries (25\%) and 12 mild dental caries $(50 \%)$. Then for 5 students with good dental health care tend to have mild caries $(20.83 \%)$. The Spearman correlation showed that there was a significant relationship between tooth health care with the number of dental caries in autistic students. It is suggested to prevent dental caries in autistic students by involving role of parents, teachers and healthcare providers.

\section{INTRODUCTION}

Autistic children generally experience dental hygiene problems compared to the normal population (Hussein et al., 2018). The prevalence of dental caries in autistic children is higher than in non-autistic children (Du et al., 2019). Dental health problems in autistic children can increase due to autism-related behaviors such as communication limitations, selfneglect, self-injurious behavior, eating habits, treatment effects, refusal to receive dental care, hyposensitivity to pain, and the possibility of avoiding social contact (Mansoor et al., 2018). Parents of autistic individuals consistently report that dental care is one of the primary needs of their children (Hariyani et al., 2019)

The problem of dental caries in autistic children is important to be chosen as the subject of research given the limited studies that report on the dental health (Leiva-García et al., 2019). If autistic children do not have good dental health, their subsequent growth and development will be hampered by problems that arise later in life They will experience self-image disturbances, difficulty eating, and can be attacked by diseases due to bacterial infections that enter together with dental caries into their bodies (Morales-Chávez et al., 2019).

As a provider of nursing care that aims to meet basic human needs, nurses should know whether the tooth health care in autistic children is closely related to a decrease in the number of dental caries (Haber and Hartnett, 2019). This is useful to improve the quality of care for autistic children, additional knowledge for those who want to know further about maintaining dental health and the number of dental caries in autistic children. 


\section{METHODS}

This research uses observational analysis descriptive research using a cross-sectional study approach, where observations on all study samples are carried out at one time and without giving treatment.

The population in this study were all autistic spectrum disorder students in SDLB (Extraordinary Elementary School) and SMPLB (Extraordinary Middle School) Bhakti Luhur Malang. The sample in this study was the entire population of autistic students in SDLB and SMPLB Bhakti Luhur Malang who were in the age range of 7-31 years (school age to young adults) to identify the relationship between increasing age and improving the quality of tooth health care. To reduce the bias of research results, samples were taken by determining the sample criteria

Inclusion criteria are the general characteristics of research subjects from an affordable target population to be studied. The inclusion criteria in this study are:

a) Autistic spectrum disorder students at SDLB and SMPLB Bhakti Luhur Malang.

b) Children who agree became respondents (with the consent of parents/guardians).

c) Children who were in a healthy condition (without complaints).

Exclusion Criteria were eliminated or excluded from the study for various reasons. Exclusion criteria in this study were:

a) Children who didn't come when the implementation takes place.

b) Children who arrived late when the implementation takes place.

c) Children who left the place when the implementation takes place.

d) Children who refused during implementation.

The sampling technique that was used in the study was total sampling. The location of the study was at the center of therapy for students of autistic spectrum disorder SDLB and SMPLB Bhakti Luhur Malang in December 2009.

The independent variable of this study was identified using a questionnaire with a closed questionnaire instrument. The respondents in this study were parents of autistic students. This closed questionnaire contained 10 questions according to existing guidelines, using closed-ended questions where the respondent's parents just choose one answer using the predetermined mark. The available answers are often, rarely, never. The answers that have been received have been tested for validity and reliability.
The method of collecting systematic observation data (direct observation using guidelines as an observation instrument) is used for the dependent variable, with the instrument being a checklist. Observations were made according to existing guidelines, based on the criteria of signs and symptoms of dental caries in children (Pribadi, 2009).

\section{RESULT AND DISCUSSION}

Respondent characteristics will be distributed based on age, sex, level of education and occupation of the respondent's parents.

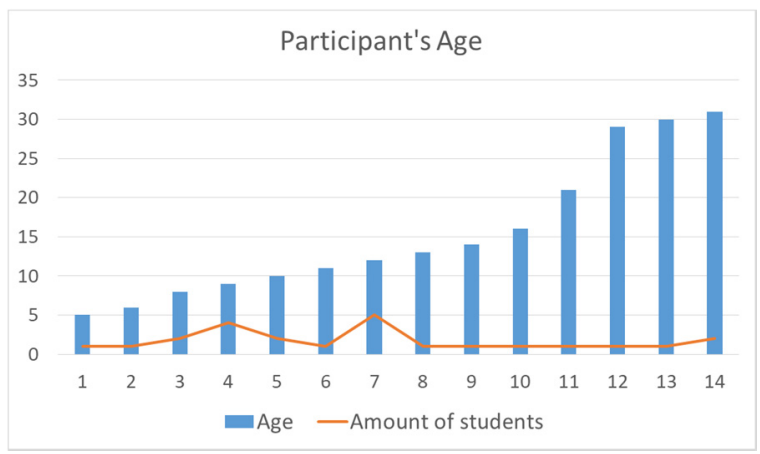

Diagram 1: Characteristics of Respondents by Age.

From the diagram 1, it can be seen that of the 24 respondents, the highest number of respondents $(20.83 \%)$ were 12-year-old students of 5 students.

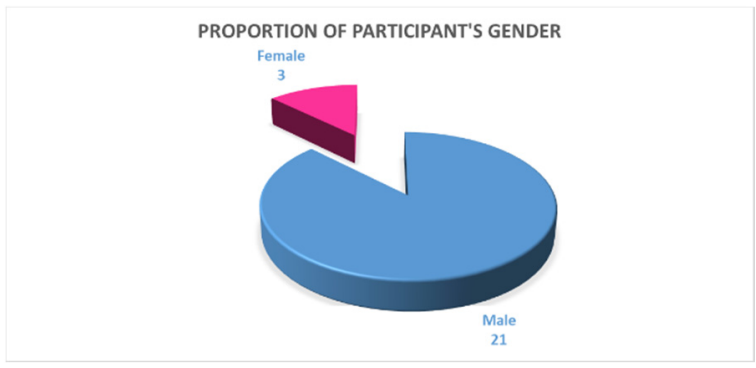

Diagram 2: Characteristics of Respondents by Gender.

From the diagram 2, it can be seen that there are 24 respondents $(100 \%)$ consisting of male and female respondents, and the majority $(87.5 \%)$ of respondents are male, namely 21 children. The rest $(12.5 \%)$ of 3 children are female students. The ratio between female respondents and male respondents is 1: 7 .

From the diagram 3, it can be seen that of the 24 respondents, the highest number of respondents 
$(33.33 \%)$ were in grade 1 SDLB, as many as 8 autistic students.

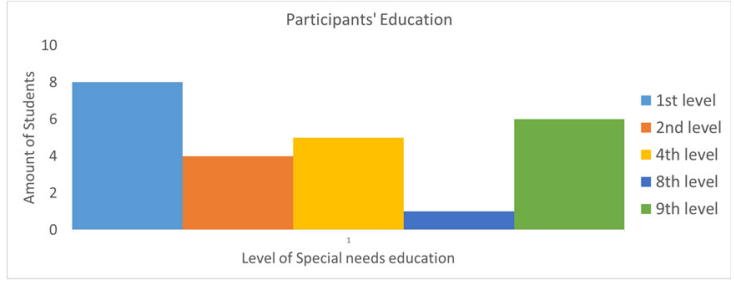

Diagram 3: Characteristics of Respondents by Education Level.

From the diagram 4, it can be seen that the majority $(51 \%)$ of respondents' parents have nonprofessional occupational backgrounds such as in the field of domestic servant services.

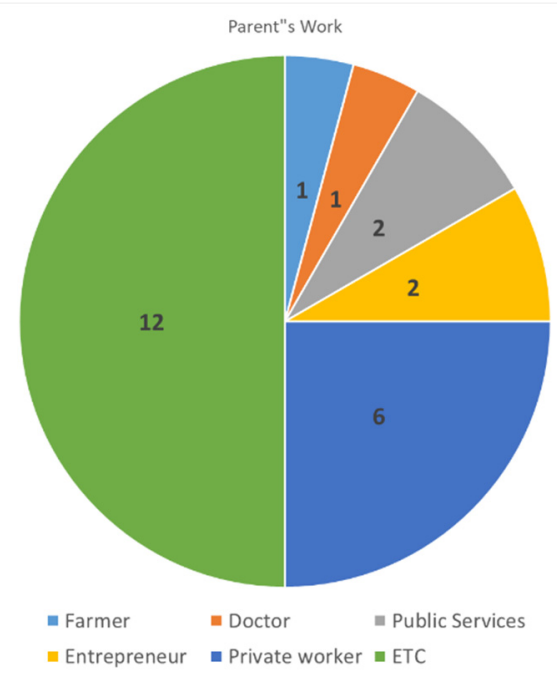

Diagram 4: Characteristics of Respondents Based on Parents' Work.

In this study, the characteristics of dental caries were examined based on the child's educational history, age of the child, and the gender of the child. The educational levels of autistic students in this study are grades 1, 2, 4 SDLB (Extraordinary Elementary Schools) and grades 2, 3 SMPLB (Extraordinary Junior High Schools). From the research data, all autistic students had dental caries. The difference lied in the number of dental caries suffered by each child. Where most dental caries $(8$ students) experienced by students in grade 1 SDLB. It was also seen that the higher the class, the number of dental caries experienced did not experience a significant decrease. This is in line with a study, that there was no significant difference in oral health status in both autistic and non-autistic as the ages increased (Kuter and Guler, 2019)

With the more mature age of individuals with autism spectrum disorders, no guarantee will increase the ability to maintain dental and oral hygiene. Each autistic individual has different abilities and levels of development depending on the type and severity of the disorder they are experiencing. Autistic individuals experience complex developmental disorders, caused by damage to the brain, resulting in disturbances to the development of communication, behavior, socialization abilities, sensory, and learning. The difference resulted from the study of Arief Fajar Pribadi (2009) in normal students at Elementary School Gedangan 04 Malang Regency grades 1,2 and 3 . The results of the study showed that the higher the grade, the number of dental caries decreased as they progressed in their development take care of his teeth health.

The results showed that the age of autistic students who experienced the most dental caries (5 students) suffered by students aged 12 years. This is supported by data from the Malang City Health Office in 2008 that the proportion of people with dental caries most of the population of the city of Malang is in the age range of 5-14 years, as many as 593 people.

Based on research, dental caries is experienced by both girls and boys. In this study, most (21 students) suffered by boys due to the influence of the number of male autistic students more than female students (Mansoor et al., 2018). This is in line with what was stated by Elvi Andriani Yusuf (2003) that autism is more common in men with a male to female ratio of 5: 1. It was also seen that the comparison of the number of teeth affected by caries in male and female students was equal, not showing more in male students or in female students. The results of this study indicate that the incidence of dental caries in autistic students is not influenced by gender (AlFatlawi and Radhi, 2017).

Based on research data it can be seen that the tooth health care in autistic students based on dental and oral hygiene, periodic examinations and types of food, in either category there is a small portion $(2.83 \%)$ or 5 students, most students are 18 children (75\%) maintenance his dental health was in the medium category, and $(4.17 \%)$ tooth health care behavior was categorized as not good.

From the data above, it can be concluded that the average tooth health care for autistic students is at a moderate level. That is because internal and external factors in maintaining their dental health have not been effective. Internal factors include behavior, age, 
sex, the severity of autism, autistic student education and the role of parents in tooth health care.

Internal factors such as the behavior of autistic students in SDLB and SMPLB Bhakti Luhur Malang which are unable to maintain their teeth independently. Very few autistic students who check their teeth to the doctor regularly every 6 months or at least when experiencing tooth pain. Autistic students also have behaviors that support an increase in the number of their dental caries. Their behavior that is difficult to control makes tooth health care which includes daily dental examinations and toothbrushes difficult to do (Du et al., 2019). Not all of them want to open their teeth, understand instructions or understand the wishes of parents/caregivers or health workers to clean their teeth. Factors of their daily habits such as eating habits held in their mouths, treatment effects, refusal to receive dental care, hyposensitivity to pain, and the possibility of avoiding social contact. There are also those who behave to damage their teeth by gouging themselves. this is as expressed by Mae Chin et. all. in 2008 in the Practical Oral Care for People with Autism article that obsessive habits, repetitive behavior, unpredictable body movements, and selfinjurious behavior may be symptoms that complicate their dental care.

Internal factors, as well as the level of education of autistic students, have less effect on improving tooth health care due to autistic spectrum disorders that are experienced causing obstacles in intellectual power, perception, and censorship. Autistic students do not have the awareness and understanding of the importance of maintaining dental health. Internal factors of autism severity influence tooth health care. The more severe the autism, the more difficult the process of cleaning teeth. Students who are still able to be trained to do motor activities will certainly facilitate them to be trained to brush their teeth. However, in more severe autism where they are truly unable to be trained to receive stimulation of external sensory perception, they are not able to participate at all in maintaining their own teeth. Internal factors in the role of parents in maintaining the dental hygiene of autistic students greatly affect the tooth health care of autistic students. Parents of students who have strong intentions, knowledge, and abilities in maintaining their son's dental health, will give their best in their son's dental care. They will routinely check their sons to the dental specialist, take care of their son's teeth properly and correctly at home, and monitor a good diet for their son's dental health. External factors in maintaining dental health are those who help in maintaining the dental health of autism students. With the limitations possessed, autistic students cannot control their own dental hygiene, so if they want optimal dental hygiene to be realized, it is needed assistance from experts, parents or caregivers. The role of health workers is very influential in dental health and prevention of dental caries in autistic students. Dental care in autistic individuals is a specialization in dental care for children with special needs who need further education to be able to master the techniques that are different from taking care of normal individuals. There are still limited institutions that provide special education for the dental care of individuals with special needs, as well as the high cost and time required to undertake the study. Parents of students/guardians are sometimes unable to fund the cost of dental care for autistic students because the costs are different and much higher than dental health care in normal individuals.

In daily life, external factors that support the maintenance of dental hygiene for students who live with their parents at home are assisted by parents, while those who live in the dormitory are assisted by caregivers/nuns owned by each child.

Not all parents understand how to care for their son's dental health and hygiene properly. From the results of the study note that most students who stay at home rarely check their dental health to the doctor regularly, so that the maintenance of clean teeth in the medium level. Their efforts are still limited to regular brushing. This can be caused by the influence of the background of parents who are busy working and do not understand about dental health. During this time they also have never received counseling regarding the tooth health care for children with autism. But for students whose parents have a background as a doctor (1 student), they have made efforts to maintain dental health by examining and caring for their son's teeth well, so that the condition of the teeth and mouth are maintained.

For students who live in the dormitory, their dental health conditions are poorly maintained and their dental health is maintained at a moderate level. In maintaining dental hygiene they were accompanied by nurses who did not have in-depth knowledge about dental health for autism students. The work done is only limited to brushing teeth twice a day. The boarding house also never brought in a dental health specialist to regularly check his health. Health workers also have never come to provide health education at the school. Plus the factor of students apart from the supervision of parents who mostly live far outside the island, thus making the health condition of their teeth less monitored. But 
there is an autistic student who lives in a dormitory whose parents always send fees to have regular dental hygiene checks every month and do maintenance. This is very different from the condition of the other friends in the hostel. So during the examination, the condition of the student's teeth was quite clean, although there were still mild caries that made cavitation.

Understanding of cariogenic food is lacking, both by caregivers and their parents. There are times when they understand that the consumption of food must be avoided but when students want it, they will give it food. This is one of the factors that triggers the presence of dental caries in those who have received regular dental treatment by a dental specialist (2 students) and is a factor that aggravates dental caries in other students who do not get an examination by a dentist.

Caregivers and parents of students also pay less attention to the diets of autistic students. They do not yet know the importance of foods containing calcium (in foods or drinks containing milk or seafood) and fluorine (in grains, supplements, vegetables and fresh fruit) as nutrients for the teeth of autistic students and prevention of dental caries.

Based on the Spearman correlation test for the relationship between tooth health care with the number of dental caries, has a correlation coefficient of -0.584 with a significance level (p) of 0.003 which is smaller than $(\alpha=0.05)$. The significance of 0.003 $(<\alpha=0.05)$ means that there is a real and convincing correlation between the 2 research variables, because the significance of the calculation is in the area of acceptance of the two-sided hypothesis test using $\alpha=$ 0.05 . Because the significance of the count $<\alpha$, then $\mathrm{Ho}$ is rejected or H1 is accepted. Thus there is a significant relationship between the tooth health care with the number of dental caries. The relationship between tooth health care with the number of dental caries has a moderate level of association, with a negative correlation direction. This means that the better the tooth health care, the less the number of dental caries.

The dental health of autistic students is influenced by the different conditions of each child. There are several factors that affect dental health, such as the habits of students who cannot control sweet foods, rarely do dental health checks to the nearest dentist or health center and the ability to maintain their own teeth hygiene is lacking.

\section{CONCLUSIONS}

The results of measurement of tooth health care for students based on dental and oral hygiene, periodic examinations, and types of food indicate that the average tooth health care and prevention of dental caries in autistic students in class 1,2,4 SDLB and in class 2,3 SMPLB Bhakti Luhur Malang is classified as moderate. So with these results it is expected to foster awareness of the parties concerned namely parents / guardians and health workers to improve dental health to be even better because of it affects the growth and development of autistic students in the future. Autistic students in class 1,2,4 SDLB and class 2,3 SMPLB all suffer from dental caries. Both male and female students have the same chance of dental caries. The highest number of dental caries was found in autistic students in grade 1 SDLB and the highest incidence of dental caries was in autistic students who were 12 years old. It is hoped that the relevant parties, namely parents / guardians and health workers, will have an active role in preventing the progression of dental caries, or doing restoration if they have reached the stage of severe caries.

There is a significant relationship $(\mathrm{p}=0.003)$ meaning that at $95 \%$ confidence interval $(\alpha=0.05)$ a significant relationship is found between the maintenance of dental health and the number of dental caries. Large correlation $(r=-0.584)$ or have a moderate relationship, with a negative correlation direction. This means that the better the maintenance of dental health, the less the number of dental caries. With the knowledge of the relationship is expected to increase primary prevention so that dental caries can be prevented.

\section{REFERENCES}

Al-Fatlawi, A. H. F. \& Radhi, N. J. M. 2017. Oral Health Status In Relation To Nutritional Status Among Institutionalized Autistic Children And Adolescents In Baghdad City, Iraq. Journal Of Baghdad College Of Dentistry, 29, 117-124.

Du, R. Y., Yiu, C. K. \& King, N. M. 2019. Oral Health Behaviours Of Preschool Children With Autism Spectrum Disorders And Their Barriers To Dental Care. Journal Of Autism And Developmental Disorders, 49, 453-459.

Haber, J. \& Hartnett, E. 2019. The Interprofessional Role In Dental Caries Management: Impact Of The Nursing Profession In Early Childhood Caries. Dental Clinics, 63, 653-661. 
Hariyani, N., Soebekti, R. H., Setyowati, D., Bramantoro, T. \& Palupi, L. S. 2019. Factors Influencing The Severity Of Dental Caries Among Indonesian Children With Autism Spectrum Disorder-A Pilot Study. Clinical, Cosmetic And Investigational Dentistry, 11, 227.

Hussein, F. J., Mustafa, A. M. \& Sabir, S. M. 2018. Dental Caries Experience And Periodontal Health Status In A Sample Of Autism Children. Zanco Journal Of Medical Sciences (Zanco J Med Sci), 22, 73-81.

Kuter, B. \& Guler, N. 2019. Caries Experience, Oral Disorders, Oral Hygiene Practices And SocioDemographic Characteristics Of Autistic Children. European Journal Of Paediatric Dentistry, 20, 237-241.

Leiva-García, B., Planells, E., Del Pozo, P. P. \& MolinaLópez, J. 2019. Association Between Feeding Problems And Oral Health Status In Children With Autism Spectrum Disorder. Journal Of Autism And Developmental Disorders, 1-12.

Mansoor, D., Al, M. H., Khamis, A. \& Kowash, M. 2018. Oral Health Challenges Facing Dubai Children With Autism Spectrum Disorder At Home And In Accessing Oral Health Care. European Journal Of Paediatric Dentistry, 19, 127-133.

Morales-Chávez, M., Villarroel-Dorrego, M. \& SALAS, V. 2019. Salivary Factors Related to Caries in Children with Autism. Journal of Clinical Pediatric Dentistry, 43, 22-26.

Pribadi, Arif F. 2009. Hubungan Antara Pemeliharaan Kesehatan Gigi dengan Indeks Karies Gigi pada Anak Usia Sekolah (Kelas 1, 2 dan 3) di SDN Gedangan 04 Kecamatan Gedangan Kebupaten Malang. 